\title{
Bronchial Fistula
}

National Cancer Institute

\section{Source}

National Cancer Institute. Bronchial Fistula. NCI Thesaurus. Code C79543.

An abnormal communication between the bronchus and another org an or anatomic site. 